\title{
Analyzing Body Values in the Context of Postmodern Youth Education. A Comparative Study Between Italy, Latvia and Romania
}

\author{
Emanuele Isidori ${ }^{1}$, Agita Abele $^{2}$, Josif Sandor ${ }^{3}$, Ioan \\ Virgil Ganea ${ }^{3}$, Francesco Taddei ${ }^{1}$, Claudia Maulini ${ }^{1}$
}

\author{
${ }^{1}$ University of Rome "Foro Italico" \\ ${ }^{2}$ Latvian Academy of Sport Education \\ ${ }^{3}$ Babes-Bolyai University of Cluj-Napoca
}

ABSTRACT

Nowadays, research on the body and the values it embodies is considered fundamental in the research field of sport studies. There is a correlation between the choice of values preferred by youth and changes taking place in contemporary society. The postmodern society is a society in which body values prevail over all other ones; the type of body values dominant in a capitalist society are mostly those which are connected to the hedonistic, esthetic and emotional dimension of the body itself.

Starting from this background, this study aims to draw the hierarchy of body values, focusing on sport sciences students at Italian, Latvian and Romanian universities, who will be future educators and professionals of body care and well-being in the European society, in order to understand their preferences and the possible cultural differences that can emerge from the three societies.

To carry out the research, a randomized sample of 300 subjects - female and male students (100 per country) - attending first-, second- and third-year sport sciences courses at the University of Rome "Foro Italico", the Latvian Academy of Sport Education in Riga, and Babes-Bolyai University of ClujNapoca were selected.

The students' values hierarchy was obtained through a Likert-scale-based questionnaire adapted and translated into Italian, Latvian and Romanian. The aim of the questionnaire was to detect the level of agreeability or disagreeability shown by each student when presented with words regarding 10 main body values models: biological body; ecological body; instrumental body; dynamic/sporting body, emotional/social body; ethical body; esthetical body; religious body; intellectual body; pleasure body.

The data obtained were statistically processed and compared. The results showed that the hierarchy of body values in young students of sports sciences is broadly in line with those of postmodern society and education, and that there are differences in the perception of values among students due 
to cultural differences and the traditions of the societies in which they live. The research also highlighted the need to develop a more effective moral education, one that focuses on ethics, in the curricula of the three universities studied.

KEYWORDS $\quad$ body, values, youth, postmodern education, sport sciences

\section{Introduction}

The human body can be considered a text that synthesizes all the dimensions of the human being. In this text, the biological dimension, and both the ontical (that is regarding values) and the ontological one (referred to the existence) meet. Our body is a hermeneutical tool and a category by which we can interpret the world. The Body is a fundamental component of education itself. Therefore we can say that the starting point of any education is always the body and that education can be seen as a process through which the human body develop from a simple condition of material and biological existence into a spiritual awareness (Isidori 2002).

The body is always something that needs to be educated (Fullat 2003). It is an entity or system that presents multiple levels of complexity (biological, psychological, social, emotional etc.). In sport pedagogy and psychology and from the phenomenology point of view, the body is seen essentially as a lived one (Erlebnis), as something that is inseparable from the experience of the person, as an integrated and integral entity not divisible into parts and comprehensible only as a whole. The body looks like a bio-physiological and culturally integrated system involving various levels of freedom and possibility.

Research on the body and the values that it embodies is now considered fundamental in the research field of sport sciences and sport studies. Sport sciences researchers have realised that the body cannot be considered an unchanging and constant fact because it is something that has to be assessed within the context of its social and cultural setting, which always define and construct it. Studying the body and its values in the context of sport and physical education can offer a new way of thinking about a human being and her/his interaction with society.

Body values are always images and depend on the society in which we live (society shapes body and bodies shape society through values in a continuous circle). Values are always expressed by bodies (who are the human beings). For this reason, there exists a strict connection among body, values and society, and if we study the body values of a person or a group of people, we have the possibility of reconstructing the images and characteristics of the society in which they live.

Sport and physical activity, as human practices involving the body, are rich in values. Sport is a concept that is always composed of three basic components: body, play/game and movement (Isidori, 2009). The importance of the body in contemporary research has led to the development of an autonomous research field called body studies (Cole 2007). This research field has been especially developed by psychologists, sociologists, philosophers and educationists of sport, who have investigated the relationship between the body and the values of the person, with particular attention given to youth education in the postmodern society (Fernández-Balboa 1997, Isidori, Fraile 2008). There exists a correlation between the choice of values preferred by youth and the changes taking place in the contemporary society (Ābele 2005 ). One can say that postmodern society is a society in which body values prevail over all the other ones; the type of body values which are dominant in the capitalist society are mostly those which are connected to the hedonistic, esthetic and emotional dimension of the body itself (Isidori 2002).

The aim of this research is to compare and evaluate the value priorities of Italian, Latvian and Romanian sport sciences students who are supposed to, as body care experts and professionals, represent a privileged observatory on body and society. The main assumption of the research was that by detecting the hierarchy of values in sport sciences students, one can better understand their attitudes 
and culture first of all; and then their way of thinking and relating not only to sport but also with the entire society and the people who there live.

In this possible hierarchy of postmodern body values, the religious ones tend to be placed as last. This occurs not only in accordance with a postmodern society's ongoing process of secularization but also with the announcement of the so-called grand narratives' eclipse (that is, first of all, ideologies and religions) (Lyotard 1984). The human body is always tied to the values of the person. According to Max Scheler (1874-1928), the values are not created by man/woman but they exist objectively and depend on human cognition. The values are different and form a hierarchy, different for each person.

One of the tools currently used to detect these preferences is represented by a test on body values (Cesares García 1995, Gervilla 2000), which was also applied to the field of sport sciences in the framework concerning sport values and youth education (Gutiérrez Sanmartín 2003).

\section{Theoretical framework}

Beginning from this hermeneutical background, this study aims to draw the hierarchy of body values in sport sciences university students, the future educators and professionals of body care and well-being in European society, in order to understand their preferences, the limitations of moral education taught in Latvian, Italian an Romanian universities, and the possible cultural differences that can emerge from the three societies.

The three countries in which this comparative research has been carried out are very different in terms of culture, language and social traditions. Italy is one of the most densely populated countries in the European Union, is a Latin country in its language and culture, and is characterized by Catholic religious traditions. Latvia, on the other hand, is one of the smaller countries of Europe, a state that formerly belonged to the USSR. It is a state that has only recently made its entry into the European Union (2004), has an official language belonging to the Baltic branch, is a place where religion plays a lesser role in its culture, and where Lutheranism is the dominant religion. Romania is a former socialist country. It joined the European Union in 2007, in which it has the ninth-largest territory and the seventh-largest population (more than 21 million people). It is a secular state but the dominant religion is the Romanian Orthodox. Romanian, a Romance language, is the official language of this state.

The scenario of this research was represented by the three most representative University centers for the study of sport sciences in the two capital cities of Italy and Latvia and in one of the most important region of Romania (Transylvania): that is Rome, Riga and Cluj-Napoca.

The University of Rome Foro Italico (URFI), the only Italian university that focuses entirely on sport sciences, is the former University Institute of Motor Sciences, a transformation of the National Institute of Physical Education and of the ancient Academy of Physical Education founded in 1927. The Latvian Academy of Sport Education (LASE) is the only - and most prestigious - university centre for the study and research in the field of sport sciences in Latvia. This institution, like the URFI in Italy, has a highly professional reputation among the other Baltic countries. The same things can be said about the 50-year-old sport sciences faculty of Babes-Bolyai University of Cluj (BBU), which is one of the oldest and most prestigious universities of Romania and Central Europe.

\section{Methods of research}

To carry out the research, about 300 subjects - female and male students (100 per country) attending first-, second- and third-year courses in sport sciences at LASE in Riga (average age $=20.59$ yr), at UFR in Rome (average age $=22.12 \mathrm{yr}$ ) and at BBU in Cluj (average age $=22.14 \mathrm{yr}$ ) were selected. The sample was randomized (about one half females and the other half males). 
The students' values hierarchy was obtained through a Spanish questionnaire (Gervilla 2000) adapted and translated into Italian, Latvian and Romanian. The questionnaire was based on a Likert scale of summated ratings. The aim of the questionnaire was to detect the level of agreeability or disagreeability shown by each student when presented with some words regarding 10 main body values models, that is: biological body (BIO); ecological body (ECO); instrumental body (INS); dynamic/sporting body (DYN), emotional/social body (EMO); ethical body (ETH); esthetic body (EST); religious body (REL); intellectual body (INT); pleasure body (PLE). These models aim to represent all the dimensions of the human body, and are based on Howard Gardner's theory of multiple intelligences (2006).

The test consisted of 10 forms, 25 words each, concerning the 10 body models identified above. An algebraic addition of the obtained scores was made. The closer the reported score for each group of 25 words was to 50 (or -50 ), the more the subject was shown to prefer (or not to prefer) that body values' model.

\section{Data analysis}

The data obtained were statistically processed using various statistic programs (mainly SPSS Statistical Package for the Social Sciences) and compared. The main analysis performed was the variance coefficient one. The following analyses were done:

- per country (see fig. 1);

- per gender (see fig. 2);

- per gender/country (see fig. 3).

Figure 1 shows that the difference is the smallest in emotional values (expected deviation from the depicted results of less than 0.05), and the greatest in all the other ones (expected deviation of less than 0.01).

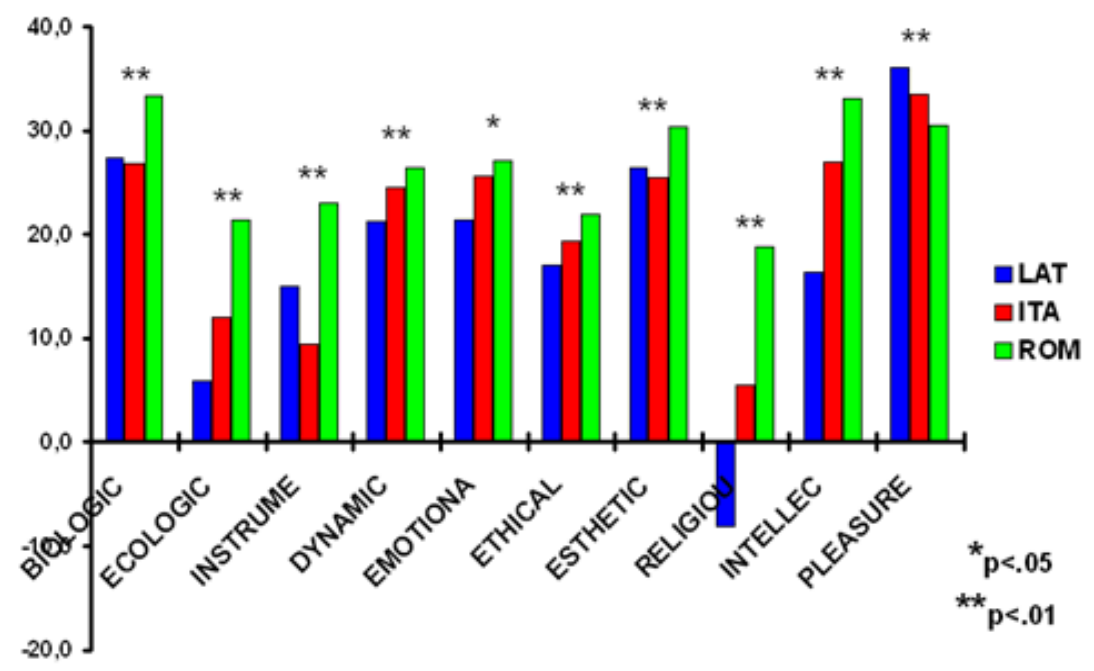

Figure 1. Analysis of variance per country

Figure 2 shows that there is a considerable difference between genders in biological and ethical values, followed by pleasure, esthetical and intellectual values, with women considering all more significant than men. 


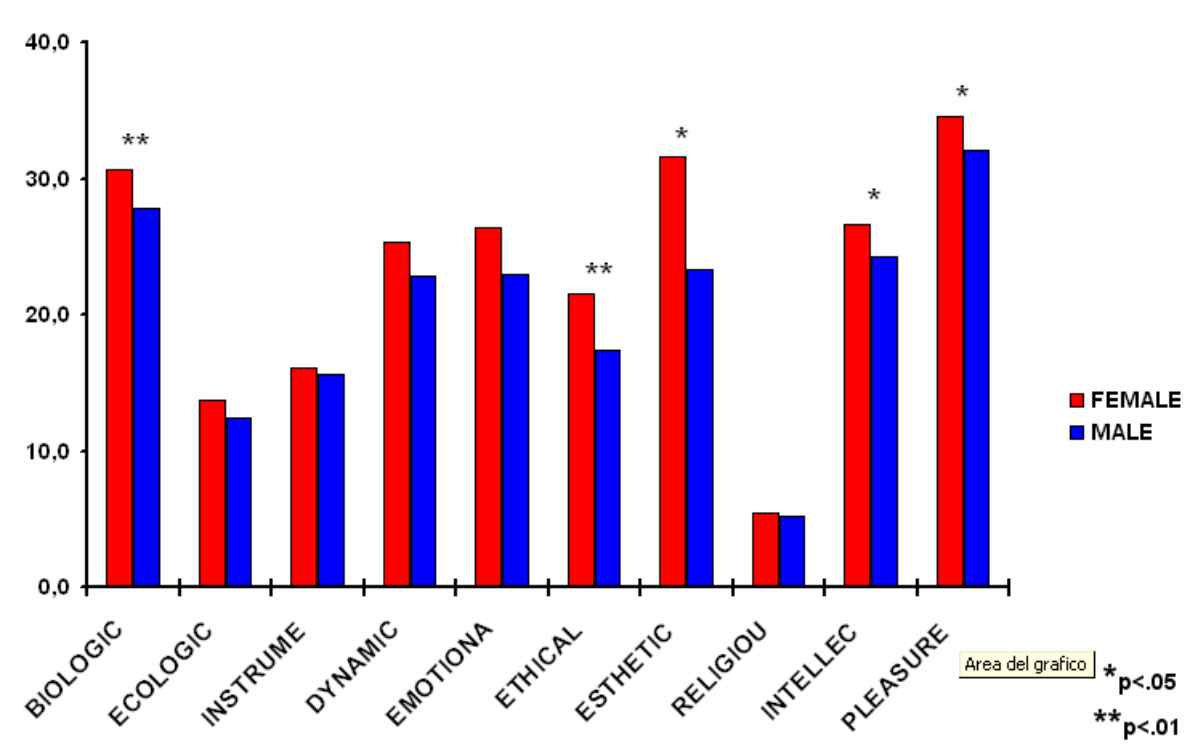

Figure 2. Analysis of variance per gender

The next figure (Figure 3) and its analysis helped both to detect the hierarchy of preference of each LASE, URFI and BBU student for each of the 10 body values models identified.

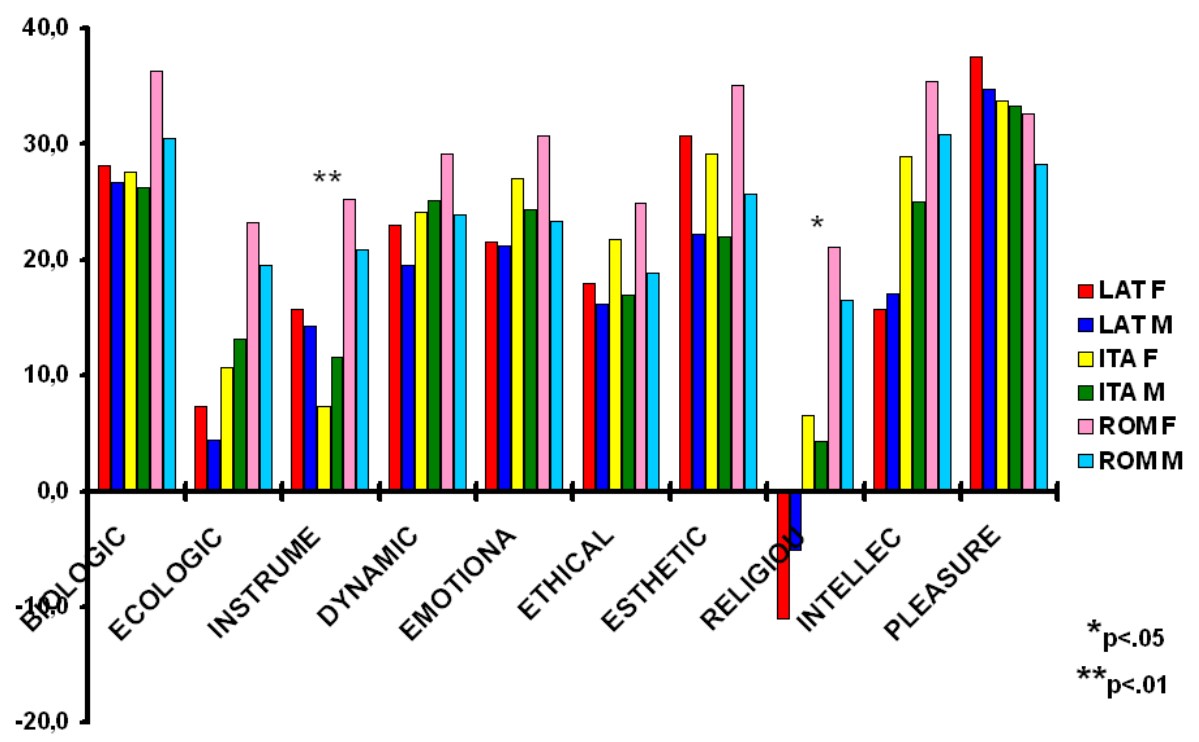

Figure 3. Analysis of variance per country and gender

The above figure demonstrates the connection between body and values (that is, thinking and behaviors) and the possible differences that exist among students due to their gender and country of birth.

\section{Results and discussion}

The research shows some differences in the perception of body values among Italian, Latvian and Romanian students. Generally speaking, and with reference to the following values, the three groups of students demonstrate the following differences:

1. Ecological/ ethical body values: the Romanian students are more sensitive and aware of these kind of values than the Italian and Latvian students.

2. Dynamic body values (that is sporting body values): the Latvian and Italian students like these body values less than their Romanian fellows.

3. Intellectual body values: Romanian students have a deeper perception of this body dimension. 
4. Instrumental body values: the practical dimension of the body is considered to be more agreeable by Romanian students.

5. Pleasure body values: the Latvian students, who appear to be more hedonistic, consider this kind of body value as the most agreeable.

Other considerations can be made about female students, who reveal special differences in:

1. Instrumental body values: females from URFI are less interested in the practical dimension of the body and they reveal themselves to be less practical than Italian male students and both Latvian and Romanian male and female students, who are the most practical.

2. Religious body values: Latvian females have a low interest in religious values, less than their Latvian, Italian and Romanian male and female mates.

3. Ethical and esthetical body values: Italian, Latvian and Romanian females are more sensitive towards these values than their fellow-countrymen. But Romanian females like these values more than all their female mates from the other countries.

All the data collected have been used to outline Italian, Latvian and Romanian sport sciences students' body values hierarchy. This hierarchy, which allows us to draw a general body values profile of Italian, Latvian and Romanian sport sciences students, has been compared.

Table 1 shows the average points of the Latvian, Italian and Romanian students' response regarding each body value while table 2 shows the arrangement of values in order of their significance in the views of these students.

Table 1. Average of body values' scores

\begin{tabular}{lcccccccccc}
\hline & BIO & ECO & INS & DYN & EMO & ETH & EST & REL & INT & PLE \\
\hline LAT & 27,4 & 5,9 & 15,0 & 21,2 & 21,4 & 17,1 & 26,5 & $-8,2$ & 16,4 & 36,1 \\
ITA & 26,9 & 12,0 & 9,5 & 24,6 & 25,7 & 19,4 & 25,5 & 5,4 & 27,0 & 33,5 \\
ROM & 33,4 & 21,4 & 23,1 & 26,5 & 27,0 & 21,9 & 30,4 & 18,8 & 33,1 & 30,5 \\
\hline $\mathrm{p}<0,0000$ & & & & & & & & & &
\end{tabular}

Table 2. Compared body values profiles of URFI, LASE and BBU sport sciences students

\begin{tabular}{clclcl}
\hline $\begin{array}{c}\text { Foro } \\
\text { Italico }\end{array}$ & $\begin{array}{l}\text { Values } \\
\text { Hierarchy }\end{array}$ & LASE & $\begin{array}{l}\text { Values } \\
\text { Hierarchy }\end{array}$ & $\begin{array}{c}\text { Babes } \\
\text {-Bolyai }\end{array}$ & $\begin{array}{l}\text { Values } \\
\text { Hierarchy }\end{array}$ \\
\hline 1 & Pleasure & 1 & Pleasure & 1 & Biological \\
2 & Intellectual & 2 & Biological & 2 & Intellectual \\
3 & Biological & 3 & Esthetic & 3 & Pleasure \\
4 & Emotional & 4 & Emotional & 4 & Esthetic \\
5 & Esthetic & 5 & Dynamic & 5 & Emotional \\
6 & Dynamic & 6 & Ethical & 6 & Dynamic \\
7 & Ethical & 7 & Intellectual & 7 & Instrumental \\
8 & Ecological & 8 & Instrumental & 8 & Ethical \\
9 & Instrumental & 9 & Ecological & 9 & Ecological \\
10 & Religious & 10 & Religious & 10 & Religious \\
\hline
\end{tabular}

Both Italian and Latvian sport sciences students, although with a considerable difference, consider pleasure values the most important (36,1 point average among Latvians and 33,5 point average among Italians). For Romanian students the most important values are not pleasure $(30,5)$ but the biological and intellectual ones. For all students religious values are considered the least important with a considerable difference (-8,2 point average among Latvians, 5,4 point average among Italians and 18,8 among Romanians, who are shown to be more religious). The compared values profiles show that students from the three countries do not consider dynamic/sporting values the most important and that they tend to put values such as the ethical and ecologic ones in the last positions. 


\section{Conclusions}

The results of this research have shown that the hierarchy of body values in young students of sport sciences in Italy, Latvia and Romania is broadly in line with those of postmodern society and education. Further, there are differences in the perception of values among students due to cultural and historical differences, curricula, and the traditions of the societies in which they live.

This research has also highlighted the need to develop a more effective moral education within the curricula of the three universities studied. This education ought to focus on ethics and environmental values, which are considered less important by students. The pedagogical point of view of this research is that all the body values are important and for this reason there are no values more or less important for education, because they always express the multidimensionality of the human being. A lack of values in any of these dimensions can obstruct a correct moral development of the youth.

The body can be thought of as existing in nature and culture at the same time. It is always culturally loaded and inscribed by the dominant values of particular cultures (Tinning 2010) and nowadays the dominant culture is the materialistic and the capitalistic one. In order to change this culture, education can perform a fundamental task. Therefore, it is important to develop a sort of theory of mastery learning for the body values that helps university students develop all the dimensions of their body and to give equal importance to all values at the same time.

Therefore, the three sport sciences universities studied must try to develop, through the use of specific teaching programs or didactic tools, curricula focusing on education for body values aimed at developing deeper moral and ethical competence in students who will be the future European sport professionals.

\section{REFERENCES}

Ābele, A. (2005). The development of values in a study process. Sbornik mezinarodni conference (pp. 178-186). Praha.

Cesares García, P. (1995). Test de valores: un instrumento para la evaluación. Revista Española de Pedagogía, 203, 513-537.

Cole, C. (2007). Body studies. In J. Coakley, E. Dunning (Eds). Handbook of sports studies (pp. 439-460). Thousand Oaks, CA: Sage.

Fernandez-Balboa, M. (Ed) (1997). Critical postmodernism in human movement, physical education and sport. Albany: SUNY.

Fullat, O. (2003). Le parole del corpo. A cura di di E. Isidori. Anicia: Roma.

Gervilla, E. (2000). Valores del cuerpo educando. Barcelona: Herder.

Gardner, H. (2006). Multiple intelligences: new horizons in theory and practice. New York: Basic Books.

Gutiérrez Sanmartín, M. (2003). Manual sobre valores en la educación física y el deporte. Barcelona: Paidós.

Isidori, E. (2002). La pedagogia come scienza del corpo. Anicia: Roma.

Isidori, E. (2009). La pedagogia dello sport. Roma: Carocci

Isidori, E., Fraile, A. (2008). Educazione, sport e valori. Un approccio critico-riflessivo. Roma: Aracne.

Lyotard, J. F. (1984). The postmodern condition: A report on knowledge. Minneapolis: The University of Minnesota Press.

Marcula, P., Pringle, R. (2006). Foucault, Sport and Exercise: Power, Knowledge and Transforming the Self. Routledge: London.

Tinning, R. (2010). Pedagogy and Human Movement. Theory. Practice, research. Routledge: New York.

\section{AUTHOR'S ADDRESS: $\quad$ Emanuele Isidori}

University of Rome "Foro Italico"

Piazza L. De Bosis, 15

00135 ROMA, Italy

Email: emanuele.isidori@uniroma4.it 